\title{
Study of sternalis muscle in north Indian population- a cadaveric study
}

\author{
Soni $S^{1}$, Bhardwaj $K^{2}$, Garg $S^{3}$ \\ ${ }^{1}$ Dr. Sachin Soni, Assistant Professor, Department of Anatomy, Veer Chandra Singh Garhwali Govt. Institute of Medical \\ Science \& Research, Srinagar, Pauri- Garhwal, Uttarakhand; ${ }^{2}$ Dr. Kamal Bhardwaj, Lecturer, Department of Anatomy, \\ S.N. Medical College, Agra; ${ }^{3}$ Dr. Shikky Garg, Associate Professor, Department of Anatomy, S.N. Medical College, \\ Agra, UP, India.
}

Address for Correspondence- Dr. Sachin Soni, Assistant Professor, Department of Anatomy, Veer Chandra Singh Garhwali Govt. Institute of Medical Science \& Research, Srinagar, Pauri- Garhwal, Uttarakhand, E Mail IDsachin.vcsg@gmail.com

\begin{abstract}
Background: Sternalis is anatomic variant of anterior thoracic region generally encountered on routine dissection, imaging procedures or surgeries. Although here is sufficient text available regarding presence and extent of sternalis muscle but state of confusion still exist regarding its nerve supply. Aim: In our study we have tried to find out the incidence of presence of sternalis muscle in north Indian population and through fine dissection, we have focused on the innervation received by the muscle. Materials and Method: 48 human cadavers including both male and female were dissected at Veer Chandra Singh Garhwali Government Institute of medical Science \& Research, Paui- Garhwal and Sarojini naidu Medical College Agra. Special emphasis was laid on innervations and through fine dissection, detailed picture about innervations was recorded. For cases with doubt, histological examination was done and final observations were recorded. Result: Sternalis muscle was reported in 4 out of 48 cadavers. All cases presented with unilateral type of sternalis muscle. Three were present in male while one in female cadaver. In one cadaver, it was innervated by medial pectoral nerve while in two, innervations were provided by intercostals group of nerves. Only one cadaver presented with dual nerve supply. Conclusion: in north Indian region, incidence of sternalis is 8.3 percent with dual innervation in single cadaver.
\end{abstract}

Keywords: Sternalis, Pectoral nerves, Intercostal nerves, Cadavers, Innervations.

\section{Introduction}

Term sternalis was mentioned in 1964 by Turner in his book "Anatomes elenchus Accuratissimus" [1]. It has been variously termed since then as Episternalis, Persternalis, Rectus Thoracis, Rectus Sterni and Superficial Rectus Abdominis. It has attracted the attention of many Anatomists, Radiologists. It is an anatomical variant of anterior thoracic region with incidence of $3-8 \%$ approximately [2, 3]. Sternalis muscle has been classified as Unilateral and Bilateral [4]. Unilateral incidence of Sternalis Muscle has been found in $4.5 \%$ subjects and Bilateral in less than 1.7 percent of the subjects [5]. Sternalis is a long, thin, flat muscle with origin at infraclavicular part of anterior

Manuscript received: $16^{\text {th }}$ April 2017

Reviewed: $25^{\text {th }}$ April 2017

Author Corrected: $3^{\text {rd }}$ May 2017

Accepted for Publication: $10^{\text {th }}$ May 2017 chest wall, running superficial to medial part of pectoralis major muscle [6]. Although, there is uniform opinion about the site and attachments of sternalis muscle, innervations issue is still a point of debate [2].

It can get nerve supply by Pectoral nerves [7] or can be innervated by anterior branches of the intercostals nerves [8]. It can get innervations from the combination of above two set of nerves altogether [9]. The functional significance of sternalis muscle is unknown but its knowledge is essential for anatomists, Radiologists and surgeons for the sake of reconstruction surgery and correct interpretation of mammograms. [6]. At times Sternalis is encountered as an irregular focal density in craniocaudal mammograms medially and may produce difficulties in mammographic interpretations [10, 11]. 
Many studies have suggested occurrence of sternalis muscle in fetuses with anomalies often fatal. Anencephaly, cleft palate and spina bifida are the common anomalies recorded in various studies with stenalis muscle.

\section{Material \& Methods}

Study design: This was a descriptive study carried out in Department of Anatomy, Veer Chandra Singh Garhwali Government Institute of Medical Science \& Research, Srinagar, Pauri- Garhwal, Uttarakhand and Sarojini Naidu Medical College, Agra.

Inclusion criteria: Cadavers received in Department of Anatomy from various sources (Unclaimed dead bodies provided by Government agencies and donated dead bodies) were studied. Both male and female cadavers were included in the study. Only adult cadavers were studied.

\section{Results}

Out of 48 cadavers 4 cadavers found to have sternalis muscle. All sternalis muscles found were unilateral. Out of 4 unilateral sternalis, One was found in a female cadaver. The detailed observations of the sternalis are as follows:

Cadaver No.1 with sternalis muscle- Unilateral sternalis muscle was present on right side in the male cadaver. It was running just over the right margin of manubrium-sterni. Upper end with tendon was blended in the tendon of right sternocliedomastoid muscle.

Moved slightly laterally and lower end got insertion in the aponeurosis of external oblique which is covering the rectus abdominis (Fig.1) Sternalis muscle was $198 \mathrm{~mm}$ long with breadth of $55 \mathrm{~mm}$ and thickness of $3.2 \mathrm{~mm}$. On further dissection and clearing, it was noticed that one branch of medial pectoral nerve supplied the muscle.

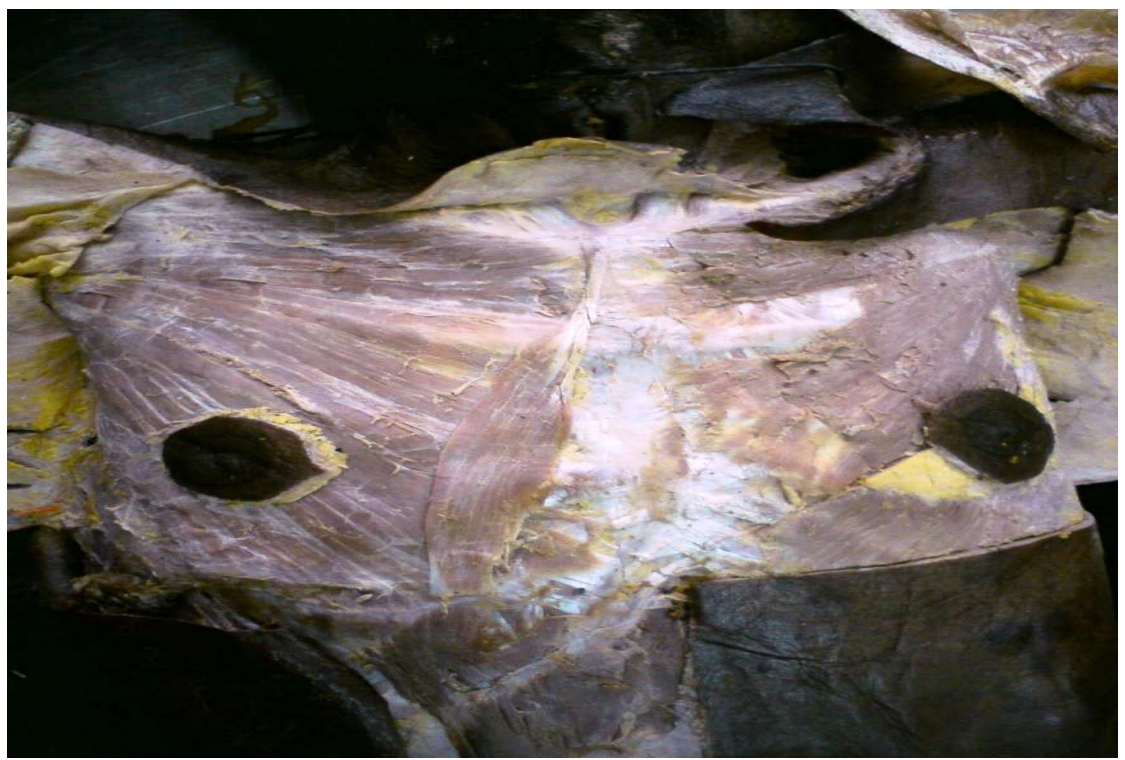

Fig-1: Right sided unilateral sternalis muscle with its extent and attachments 


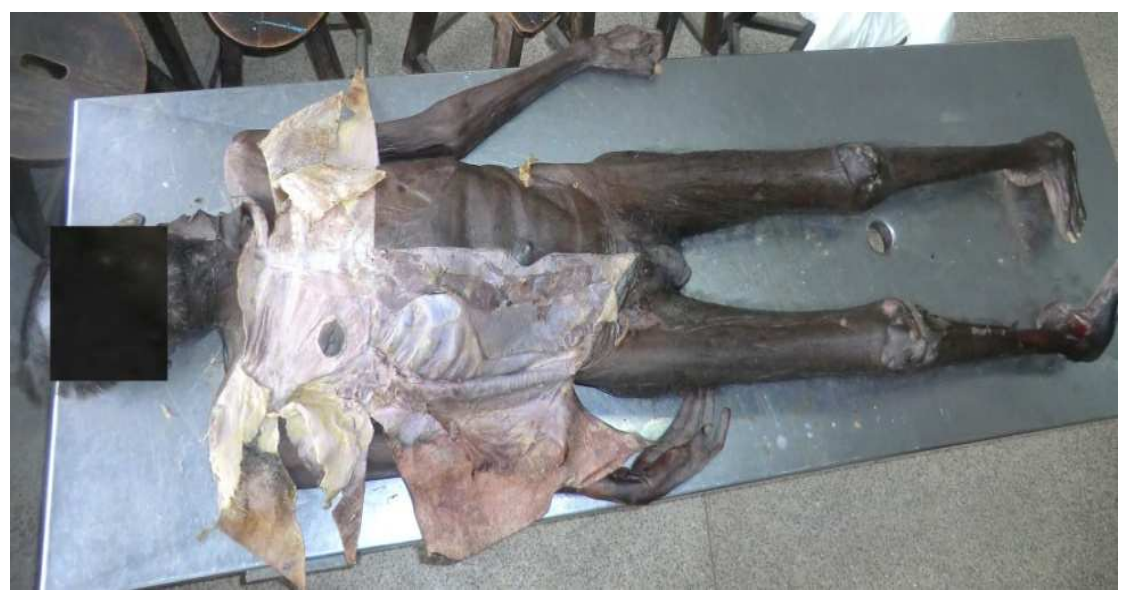

Fig-2: Cadaver with right sided unilateral sternalis muscle and CTEV

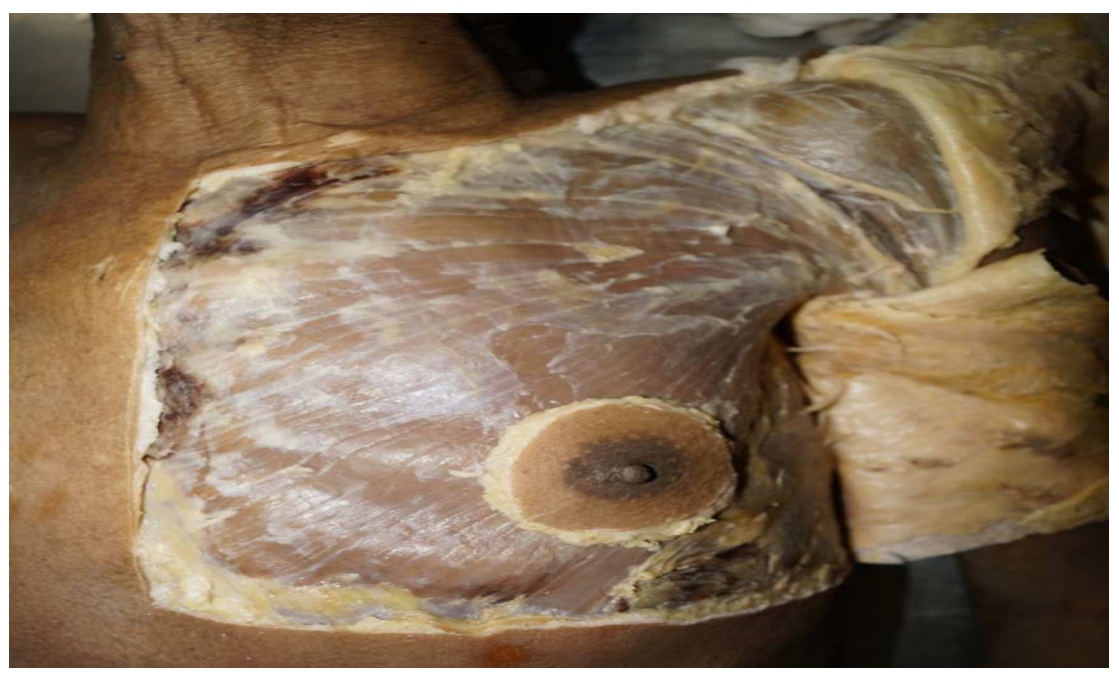

Fig-3: left sided incomplete unilateral sternalis muscle

One more remarkable point associated with same cadaver was that, it suffered with Congenital Talpies Equino Varus (C.T.E.V.). (fig. 2).

Cadaver No.2 with sternalis muscle- Unilateral sternalis muscle was present on the left pectoral region of male cadaver. It was incomplete scattered in two parts. First part was just lying lateral to manubrium while second part was noticed over $3^{\text {rd }}$ to $5^{\text {th }}$ costal cartilage.(Fig-3) It mimicked like some blood clot and to differentiate it from blood clot, sample was taken and histology slides were prepared. On light microscopic examination, it was confirmed as skeletal muscle that is Sternalis muscle. Both upper and lower parts of the muscle were lying freely over Pectoralis major and margin of sternum in fascia over it. No tendenous attachments were established. Upper part was $58 \mathrm{~mm}$ long, $12 \mathrm{~mm}$ wide and $2.6 \mathrm{~mm}$ thick while lower part was $42 \mathrm{~mm}$ long, $9 \mathrm{~mm}$ wide and $2.8 \mathrm{~mm}$ thick. Lower part was getting innervations via intercostals nerve. Nerve supply for upper part was not found.

Cadaver No. 3 with sternalis muscle- The unilateral sternalis was present over the right pectoral region of female cadaver. It ran right below the tendon of sternocliedomastoid of right side just over pectoralis major on side of sternum. It ended by blending in to the aponeurosis of external oblique running over rectus abdominis. It was $154 \mathrm{~mm}$ long $42 \mathrm{~mm}$ wide and $2.6 \mathrm{~mm}$ thick.

On further fine dissection, a branch of medial pectoral running in between fibres of pectoralis major muscle was seen which was supplying the muscle along with $3^{\text {rd }}$ intercostals nerve. The dual nerve supply is shown in fig.no.4. 


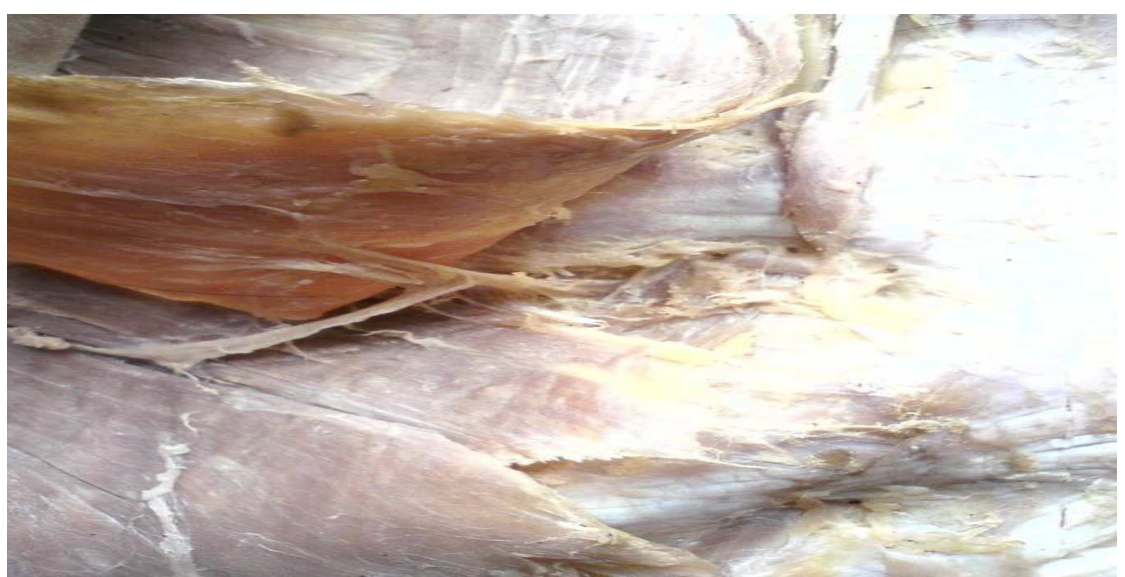

Fig-4: dual nerve supply of sternalis muscle from intercostals and pectoral nerves

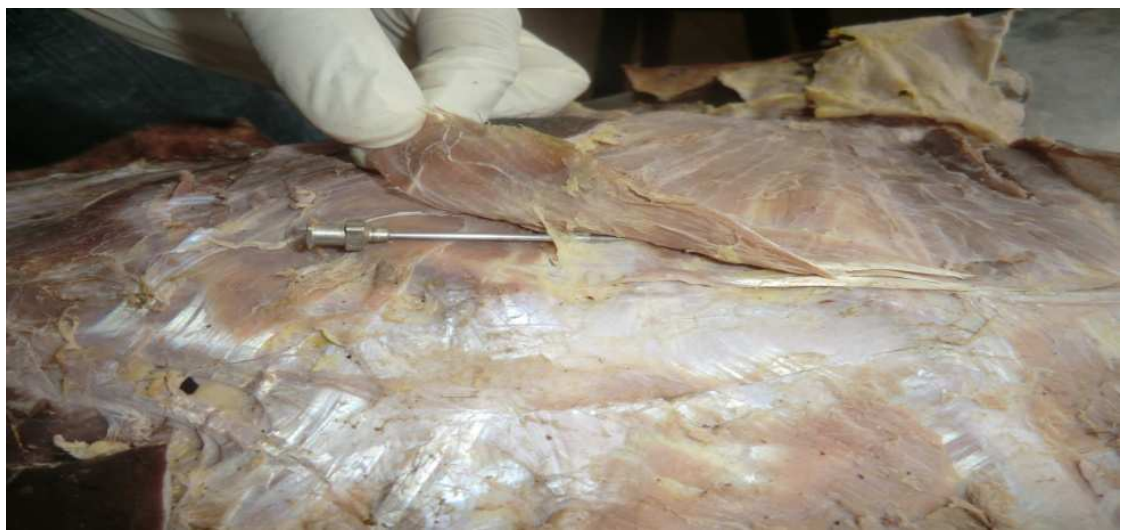

Fig-5: sternalis muscle getting innervations from intercostal nerve

Cadaver no.4 with sternalis muscle- The unilateral sternalis muscle was situated on the right side of the male cadaver. The upper end was attached to the tendon of sternocliedomastoid and lower end was attached to $5^{\text {th }}$ and $6^{\text {th }}$ costal cartilage and external oblique aponeurosis covering rectus abdominis.

Muscle travelled over margin of sternum. It was $163 \mathrm{~mm}$ long $34 \mathrm{~mm}$ wide and $2.8 \mathrm{~mm}$ thick with tendon at upper end and belly at lower end. On fine dissection it was found that $4^{\text {th }}$ intercostal nerve is supplying the muscle (fig.5)

\section{Discussion}

General incidence varies between races [12]. In European population it varies from $2-3 \%$ [13] to $6.4 \%$ [14], about $11 \%$ in Africans, [13] and from 1\% [15] to $13.1 \%$ [13] in Asian population. In Indian context it varies from $2 \%$ [16] to $8 \%[17,18]$. In our study the overall incidence of Sternalis muscle stood at $8.33 \%$. The incidence of unilateral Sternalis muscle in comparison to bilateral Sternalis muscle is twice as reported [19]. In our study we found only unilateral Sternalis muscle and no bilateral case was recorded. There was a significant difference in presence of Sternalis muscle on right and left side. 3 cases of Sternalis muscle were reported on right side where as only 1 was recorded on left side. The incidence of
Sternalis muscle was recorded equal in males and females as reported by Barlow [14] while few studies recorded it more in females $(8.7 \%)$ than in males $(6.4 \%)$. The higher reporting of incidence in females may be confounded by high rates of surgery and medical imaging for breast related conditions in females [2]. In north Indian region the lack of female cadavers for dissection can also be a confounding factor for this higher incidence reported in females. In our study in $7.692 \%$ male cadavers Sternalis muscle was present in comparison to $11.11 \%$ in female cadavers.

Many theories regarding embryological origin of Sternalis muscle have been laid down. Many say it can 
be cranial extension of rectus abdominis or caudal continuation of sternocleoid or displaced pectoral muscle fibers or remnants of pannicules carnosus $[2,7$, $14,20]$. No single theory completely explains occurance of Sternalis muscle. As per Gray's Anatomy, Sternalis muscle /rectus sternalis is superficial vertical slip that ascends upwards from lower costal cartilage and rectus sheath to attach to the upper sternum or costal cartilage or strnoclidomastoid [21].

There is much discussion \& debate about innervations of Sternalis muscle. Many reported it as pectoral nerves and others as intercostals nerves. In our first case with right sided unilateral Sternalis muscle, we found the innervation was provided by a branch of medial pectoral nerve. Researchers [7,22,23] reported innervations of Sternalis muscle from either medial or lateral pectoral nerves. In our second and fourth male cadavers with Sternalis muscle we found that muscle was innervated by inter costal nerve. Similar observations were found in other studies [4,6,24-27]. In our third female cadaver with Sternalis muscle we reported dual nerve supply from branches of both medial pectoral nerve and third intercostals nerve [7]. $55 \%$ Sternalis muscle were supplied by pectoral nerve, $43 \%$ by intercostals nerve and $2 \%$ from both pectoral and intercostals nerves. Dual nerve supply was also reported to be $4.8 \%$, from intercostal nerves $26.7 \%$ and pectoral nerves $68.5 \%$ by [14]. Fine nerve fibres may lay difficulty in dissection and identification of innervations of Sternalis muscle [7, 28].

Sternalis muscle is often associated with anomalies as nearly $50 \%$ incidence of Sternalis muscle is reported in anencephaly by [29]. As per Harish and Gopinath, 2003 [30]; presence of Sternalis muscle is associated with anomales of the skull and adrenal gland. Two foetuses with anencephaly and three with spina bifida were reported with Sternalis muscle by Harper [31].

Anencephaly fetuses were observed by Sheppard [26] with Sternalis muscle, out of them 6 have had underdeveloped pectoralis major (strenomastoid part), 1 have had cleft palate and 7 have had spina bifida. In our study one male cadaver with right sided unilateral Sternalis muscle was having Congenital Talipes Equino Varus (C.T.E.V.). Till today no such case of Sternalis muscle with C.T.E.V was reported.

No certain motor function has been reported from previous literature. It is proposed that Sternalis muscle may contribute to proprioceptive function [32]. Kirk [33] reported that in a living case with Sternalis muscle where it contracted with active trunk flexion and arm adduction.

Most researchers emphasized the importance of and need for increased knowledge and awareness of Sternalis muscle [33]. Nuthakki et al 2007[35] and Gokter et al 2006[36] on mammography and MRI identified Sternalis muscle cases. Young lee et al 2006 found 86 cases of Sternalis muscle through CT chest scans [5]. Other authors also reported that proper identification of Sternalis muscle may avoid unnecessary exploratory surgery as it may mimic carcinoma on imaging [23,37].

Harish and Gopinath [38] recorded 8 out of 1152 patients undergone radical mastectomy.Few researchers suggest that Sternalis muscle must be removed in radical mastectomy in breast Carcinoma due to its closeness [39] while few are using it as tissue exapnders material for breast reconstitution after mastectomy [40]. Our study reported the Sternalis muscle cases on pure dissection of cadavers.

\section{Conclusion}

In our study we found 4 cadavers with unilateral sternalis muscle out of 48 cadavers dissected. It was present only in one female cadaver rest all were males. One sternalis muscle was supplied by branch of medial pectoral nerve, two with intercostal nerves and dual nerve supply was also reported in one cadaver with sternalis muscle. We found male cadaver with right sided sternalis muscle suffered with Congenital Talipes EquinoVarus (C.T.E.V.).

The knowledge of sternalis muscle is crucial, especially among peoples involved in imaging of pectoral region. It is often associated with many congenital anomalies as seen in one of our case. This could help in finding out more cases of sternalis muscle.

\section{Funding: Nil, Conflict of interest: None Permission of IRB: Yes}

\section{References}

1. Bilodi AS, Sasikala P, Anuradha P, Karthikeyan V. A study on muscle variant - rectus sternalis. World Journal of Pharmacy and Pharmaceutical Sciences. 2015;4(4):1035-40. 
2. Pérez J, Pérez-Gumá JE, Correa R, Rivera M, Castro A, Cedeño J, López M, Nazario L, Otero K, Quiles J, Sánchez P. Breast mass or sternalis muscle? P R Health Sci J. 2008 Jun;27(2):185.

3. Hung LY, Lucaciu OC, Wong JJ. Back to debate: Sternalis muscle. Int. J. Morphol.2012;30(1):330-336.

4. Jelev L, Georgiev G, Surchev L. The sternalis muscle in the Bulgarian population: Classification of sternales. J Anat. 2001;199:359-63.

5. Young Lee, B.; Young Byun, J.; Hee Kim, H.; Sook Kim, H.; Mee Cho, S.; Hoon Lee, K.; Sup Song, K.; Soo Kim, B. \& Mun Lee, J. The sternalis muscles: incidence and imaging findings on MDCT. J. Thorac. Imaging. 2006 Aug 21(3):179-83.

6. Saeed M, Murshid KR, Rufai AA, Elsayed SE, Sadiq MS. An anatomic variant of chest wall musculature. Neurosciences 2002 Dec;Vol. 7(4):248-255.

7. Kida MY, Izumi A, Tanaka S. Sternalis muscle: topic for debate. Clin Anat. 2000;13(2):138-40.

8. Sarikçıoglu, L., Demirel, B. M., Oguz, N. \& Uçar, Y. Three sternalis muscles associated with abnormal attachments of the pectoralis major muscle. Anatomy. 2008; 2:67-71.

9. O'Neill, M. N. \& Folan-Curran, J. Case report: bilateral sternalis muscles with a bilateral pectoralis major anomaly. J. Anat. 1998; 193(2):289-92.

10. Britton CA, Baratz AB, Harris KM. Carcinoma mimicked by the sternal insertion of the pectoral muscle. AJR 1989 Nov; 153: 955-956.

11. Britton CA. Subpectoral mass mimicking a malignant breast mass on mammography. AJR Am J Roentgenol. 1992 Jul;159(1):221.

12. Arráez-Aybar, L. A.; Sobrado-Perez, J. \& MeridaVelasco, J. R. Left musculus sternalis. Clin. Anat., 2003 Jul; 16(4):350-4.

13. Turner W. On the Musculus Sternalis. J Anat Physiol. 1867;1(2):246-378.25.

14. Barlow, R. N. The sternalis muscle in American whites and negroes. Anat. Rec. 1935; 61(4):413-26.
15. Jeng H, Su SJ. The sternalis muscle: an uncommon anatomical variant among Taiwanese. J Anat. 1998 Aug;193 (Pt 2):287-8.

16. Mehta V, Arora J, Yadav Y, Suri RK, Rath G. Rectus thoracis bifurcalis: a new variant in the anterior chest wall musculature. Rom J Morphol Embryol. 2010; 51(4):799-801.

17. Mishra BD. The sternalis muscle. J Anat Soc India 1954; 3: 47-48.

18. Shah AC. The sternalis muscle. Indian J Med Sci. 1968 Jan;22(1):46-7.

19. Bailey PM, Tzarnas CD. The sternalis muscle: a normal finding encountered during breast surgery. Plast Reconstr Surg. 1999 Apr;103(4):1189-90.

20. Humphry GM. Lectures on the Varieties in the Muscles of Man. Br Med J. 1873 Jun 21;1(651): 693-6.

21. Gray's anatomy: the anatomical basis of clinical practice Standring, Susan; Gray, Henry, 1825-1861 Anatomy. 40th ed., anniversary ed. [Edinburgh]: Churchill Livingstone/Elsevier, 2008.

22. Wallace D. Nerve Supply of Musculus Sternalis. J Anat Physiol. 1886 Oct;21(Pt 1):153-4.

23. Kumar, H.; Rath, G.; Sharma, M.; Kohli, M. \& Rani, B. Bilateral sternalis with unusual left-sided presentation: a clinical perspective. Yonsei Med. J. 2003 Aug; 44(4):719-22.

24. Shen CL, Chien CH, Lee SH. A Taiwanese with a pair of sternalis muscles. Kaibogaku Zasshi. 1992 Oct; 67(5):652-4.

25. Shepherd FJ. Musculus Sternalis and its NerveSupply. J Anat Physiol. 1889 Jan; 23 (Pt 2): 303-7.

26. Shepherd FJ. The Musculus Sternalis and its occurrence in (Human) Anencephalous Monsters. J Anat Physiol. 1885 Apr;19(Pt 3):310.2-319.

27. Jeng H, Su SJ. The sternalis muscle: an uncommon anatomical variant among Taiwanese. J Anat. 1998 Aug;193 ( Pt 2):287-8. 
28. Loukas M, Bowers M, Hullett J. Sternalis muscle: a mystery still. Folia Morphol (Warsz). 2004 May; 63 (2):147-9.

29. Windle BC. The Myology of the Anencephalous Foetus. J Anat Physiol. 1893 Apr;27(Pt 3):348-53.

30. Harish K, Gopinath KS. Sternalis muscle: importance in surgery of the breast. Surg Radiol Anat. 2003 Jul-Aug;25(3-4):311-4. Epub 2003 Aug 1.

31. Harper WF. The Sternalis Muscle in the Anencephalous Foetus. J Anat. 1936 Jan;70 (Pt 2): 317-20.

32. Zaher, W. A.; Darwish, H. H.; Abdalla, A, M. E.; Vohra, M. S. \& Khan, M. M. Sternalis: A Clinically Important Variation. Pak. J. Med. Sci. 2009; 25(2): 325-8.

33. Kirk TS. Sternalis Muscle (in the Living). J Anat. 1925 Jan;59(Pt 2):192.

34. Rahman NA, Das S, Maatoq Sulaiman I, Hlaing KP, Haji Suhaimi F, Latiff AA, Othman F. The sternalis muscle in cadavers: anatomical facts and clinical significance. Clin Ter. 2009;160(2):129-31.
35. Nuthakki S, Gross M, Fessell D. Sonography and helical computed tomography of the sternalis muscle. $\mathbf{J}$ Ultrasound Med. 2007 Feb;26(2):247-50.

36. Goktan, C.; Orguc, S.; Serter, S. \& Ovali, G. Y. Musculus sternalis: a normal but rare mammographic finding and magnetic resonance imaging demonstration. Breast J. 2006; 12(5):488-9.

37. Pojchamarnwiputh, S.; Muttarak, M.; NaChiangmai, W. \& Chaiwun, B. Benign breast lesions mimicking carcinoma at mammography. Singapore Med. J. 2007; 48(10):958-68.

38. Harish K, Gopinath KS. Sternalis muscle: importance in surgery of the breast. Surg Radiol Anat. 2003 Jul-Aug;25(3-4):311-4. Epub 2003 Aug 1.

39. Kabay B, Akdogan I, Ozdemir B, Adiguzel E. The left sternalis muscle variation detected during mastectomy. Folia Morphol (Warsz). 2005 Nov;64 (4): 338-40.

40. Schulman, M. R. \& Chun, J. K. The conjoined sternalis-pectoralis muscle flap in immediate tissue expander reconstruction after mastectomy. Ann. Plast. Surg. 2005 Nov; 55(6):672-5.

\section{How to cite this article?}

Soni S, Bhardwaj K, Garg S. Study of sternalis muscle in north Indian population- a cadaveric study. Int J Med Res Rev 2017;5(05):448- 454. doi:10.17511/ijmrr. 2017.i05.02. 